\title{
Therapeutic effects of Salvia miltiorrhiza injection combined with telmisartan in patients with diabetic nephropathy by influencing collagen IV and fibronectin: A case-control study
}

\author{
JIE-MING NIE ${ }^{1}$ and HAI-FENG LI ${ }^{2}$ \\ ${ }^{1}$ Department of Internal Medicine, The Third Affiliated Hospital of Guangzhou Medical University, \\ Guangzhou, Guangdong 510150; ${ }^{2}$ Department of Pharmaceutical Analysis, \\ ALK-Abello A/S Guangzhou Office, Guangzhou, Guangdong 510620, P.R. China
}

Received January 19, 2018; Accepted August 1, 2018

DOI: 10.3892/etm.2018.6654

\begin{abstract}
Involvement of collagen IV (ColIV) and fibronectin (FN) in the occurrence and development of diabetic nephropathy (DN) and the effects of telmisartan and Salvia miltiorrhiza injection in the treatment of the patients were investigated. Two hundred and fifty-eight patients with stage IV DN were selected as the case group, and another 110 normal healthy subjects were incorporated as the control group. Involved patients were subdivided into different groups according to different treatment therapies; patients in the telmisartan group ( $\mathrm{T}$ group) were given oral telmisartan; patients in the Salvia miltiorrhiza injection + telmisartan ( $\mathrm{S}+\mathrm{T}$ group) were administered with Salvia miltiorrhiza injection combined with telmisartan treatment, and there was a group of patients who received no intervention as the placebo group. After intervention, levels of glycemic indexes and renal damage indexes indicated downwards trends both in the $\mathrm{T}$ group and the $\mathrm{S}+\mathrm{T}$ group when compared to the placebo group; besides, levels in the $\mathrm{S}+\mathrm{T}$ group were much lower than those in the $\mathrm{T}$ group (all $\mathrm{P}<0.05$ ). Additionally, in comparison among the above three intervention groups, differences in the fasting blood glucose, $2 \mathrm{~h}$ post-prandial blood glucose, glycosylated hemoglobin, blood urea nitrogen, serum creatinine and urinary albumin excretion rate were significant after treatment (all $\mathrm{P}<0.05)$. Further, before intervention, both ColIV and FN in the urine were increased in the case group compared to the control group (all $\mathrm{P}<0.05)$. After intervention, both levels were apparently decreased. There were remarkable differences of ColIV and FN levels in the urine when compared among
\end{abstract}

Correspondence to: Dr Hai-Feng Li, Department of Pharmaceutical Analysis, ALK-Abello A/S Guangzhou Office, RM903, B2 Building, Site 5 of 99, Jiang Nan Da Dao Road, Haizhu, Guangzhou, Guangdong 510620, P.R. China

E-mail: lcwayy@163.com

Key words: collagen IV, fibronectin, diabetic nephropathy, Salvia miltiorrhiza injection, telmisartan, glomerular basement membrane three different intervention groups after treatment $(\mathrm{P}<0.05)$. Increased ColIV and FN levels may be partially responsible for the development of DN. Salvia miltiorrhiza injection with telmisartan have beneficial synergistic effects for DN patients through attenuating the increase in ColIV and FN, reversing hyperglycemia state and postponing ultrastructure changes of glomerular basement membrane.

\section{Introduction}

Diabetes is a group of metabolic diseases characterized by a sustained increase of high blood glucose levels over a prolonged period, acting as one of the leading causes of morbidity and mortality worldwide; type 1 diabetes (T1D) and type 2 diabetes (T2D) are the two major types (1). Diabetic nephropathy (DN) is estimated to be one of the major serious chronic complications in patients with diabetes, affecting approximately one third of people with T1D or T2D (2). The rising tide of DN may be greatly associated with the dramatically increasing rate of diabetes population currently, with concomitant increase in associated cardiovascular mortality and end-stage renal disease, producing significant social and economic ramifications in the developing world particularly $(3,4)$. According to its pathophysiological changes, DN can be divided into the following five stages: glomerular filtration and renal hypertrophy stage (stage I), normal albumin urine stage (stage II), early stage of DN (stage III), clinical stage of DN (stage IV), and end stage renal failure (stage V). Main known risk factors affecting progression of DN include baseline albumin excretion, senior age, glucose/lipids/protein metabolism disorders, blood pressure, oxidative stress, hemodynamic changes and the involvement of varieties of cytokines/inflammatory factors, but the above factors fail to explain all of the interindividual variability for the rates of developing DN (5).

Collagen IV (ColIV or Col4) is an exclusively distributed collagen within the basement membrane zone, of which the basement membrane is an extracellular matrix (ECM) separating connective tissue from epithelia, endothelia, muscle fibers and the entire nervous system $(6,7)$. Mutations of the gene coding for ColIV may cause thinning and splitting 
of the glomerular basement membrane, which present as isolated hematuria, sensorineural hearing loss, and ocular disturbances $(8,9)$. Clinically, the deposition of ColIV in the liver may induce liver fibrosis and cirrhosis, whereas decreased levels may be found in serum or hepatic tissues following successful treatment (10). In addition, increased glomerular and mesangial deposition of ColIV may be positively correlated with the extent of renal injury, and thereby partially responsible for the development of DN (11). On the other hand, fibronectin (FN) is a high-molecular weight glycoprotein of the ECM binding to membrane-spanning receptor proteins called integrin (12). Similar to integrin, FN can bind ECM components such as collagen, fibrin, and heparan sulfate proteoglycans (13). Furthermore, FN plays a major role in cell adhesion, growth, migration, and differentiation, and it is important for wound healing and embryonic development (14-16). Altered FN expression, degradation, and/or organization have been associated with a number of pathological changes, including fibrosis and cancer $(17,18)$.

Because of the pathogenic complexity of $\mathrm{DN}$, new therapeutic interventions targeting primary mechanisms contributing to renal damage are critical for the future treatment of this disease. In clinical care, according to the objective and intuitive analysis of the human body, as well as corresponding etiological analysis based on anatomy and physiology, western medical treatment focuses on the control of blood glucose and blood pressure, swelling reduction, control of protein uria and protection of renal function, significantly different from traditional Chinese medicine, strengthening a balance of yin and yang on the basis of the yin and yang theory $(19,20)$. Telmisartan is an angiotensin II receptor antagonist [angiotensin receptor blocker (ARB)] which is mainly used in treating hypertension (21). At present, angiotensin converting enzyme inhibitors (ACEI) and ARB have attracted extensive attention in the treatment of DN. Studies have shown that ACEI and ARB can significantly reduce the progression of proteinuria and maintain the stability of serum creatinine (Scr) mainly through hemodynamic and nonhemodynamic mechanisms $(22,23)$. However, the exact mechanism of the latter is unclear. Furthermore, Salvia miltiorrhiza injection is isolated and extracted from the root of Salvia miltiorrhiza known as Danshen (24). Danshen is a traditional Chinese medicine that can activate the anti-oxidization system in the body to eliminate freeradicals and to prevent calcium overload (25). The injection of Salvia miltiorrhiza have been used commonly and successfully clinically for treating cardiovascular diseases $(26,27)$. For example, such injection has been suggested to scavenge the oxygen free radicals generated from ischemia-reperfusion injury in the myocardium as effectively as SOD (28). Yet related application and potential mechanism for its therapeutic basis is poorly understood for DN patients.

In this study, we aimed to investigate the roles of ColIV and FN in kidney of DN patients and the curative effects of telmisartan and Salvia miltiorrhiza injection, and to explore the mechanism of ColIV and FN taking part in the occurrence and development of DN and the possible nonhemodynamic mechanisms of telmisartan and Salvia miltiorrhiza injection to protect the kidneys. Our study might provide theoretical basis for the pathogenesis, prevention and treatment of DN.

\section{Materials and methods}

Ethics statement. All procedures performed in studies involving human participants were approved and permitted by the Ethics Committee of the Third Affiliated Hospital of Guangzhou Medical University (Guangzhou, China), in accordance with the ethical standards of the institutional and/ or national research committee and with the 1964 Helsinki declaration and its later amendments or comparable ethical standards. All the patients signed the informed consents before the investigation.

Subjects' selection. A total of 258 patients diagnosed with stage IV DN were selected in the Third Affiliated Hospital of Guangzhou Medical University from January 2014 to January 2015 as the research subjects (Clinical registration number of ChiCTR-IPR-17011581). The diagnosis of diabetes mellitus was confirmed according to the definition, diagnosis and classification of diabetes mellitus proposed by the World Health Organisation (1999), with fasting blood glucose $(\mathrm{FBG}) \geq 7.0 \mathrm{mmol} / 1(126 \mathrm{mg} / \mathrm{dl})$ or OGTT $2 \mathrm{~h}$ plasma glucose $\geq 11.1 \mathrm{mmol} / 1$ or symptoms of diabetes + the levels of blood glucose detected at any time $\geq 11.1 \mathrm{mmol} / 1$ (200 mg/dl). Stage IV DN was diagnosed and staged in accordance with the internationally recognized Mogensen staging criteria (29) namely the urinary albumin excretion rate (UAER) $>300 \mathrm{mg} /$ day at least 2 times within 6 months.

Stage IV DN patients were incorporated and patients with other causes of renal damage were excluded from this study, in combination with the following inclusion criteria: i) patients with clear history of diabetes; ii) UAER >20 g/min $(30 \mathrm{mg} / \mathrm{l})$, or positive urinary protein or $24 \mathrm{~h}$ urine quantitative protein $>0.5 \mathrm{~g}$ determined by conventional detection method; iii) patients with mild renal function ( $\mathrm{Scr}<265 \mathrm{umol} / \mathrm{l})$; iv) patients who met the above diagnosis criteria; v) patients with age ranged from 18-70 years. Exclusion criteria: i) patients who were clinically confirmed with nephritis, urinary tract infection, renal vascular disease and urinary tract obstruction diseases that could cause proteinuria; ii) pregnant or lactating women; iii) patients who had grievous heart, liver, renal dysfunction; iv) patients with thyroid disease, Cushing disease and other diseases of the endocrine system; v) patients of allergic constitution or allergic to the present medicine; vi) psychiatric patients and who were unable to cooperate properly; vii) patients younger than 18 years and aged more than 70 years. Furthermore, patients who had incomplete data during the experiment were also excluded from this study. According to the random number table method, enrolled patients were equally divided into three groups, 86 cases in each group; patients in two groups received drugs treatment, and patients in another group received placebo therapy. In addition, a total of 110 age and sex-matched normal healthy subjects receiving health examination in the same hospital were incorporated in this study during the same period, without diabetes history in the kidney examination and imaging detection. Baseline characteristics of all the subjects are listed in Table I, including sex, age, disease duration, blood pressure, total cholesterol (TC), triglycide (TG), high density lipoprotein cholesterol (HDL-C), low density lipoprotein cholesterol (LDL-C), very low density lipoprotein cholesterol 
(VLDL-C), FBG, 2 h post-prandial blood glucose (2h PBG), and glycosylated hemoglobin (HbA1c), blood urea nitrogen (BUN), Scr and UAER.

Sample collection. Both the blood samples and urine samples were collected from all the included subjects. Venous blood samples $(5 \mathrm{ml})$ were obtained from each subject early in the morning after overnight fasting. Supernatants were harvested by centrifugation $\left(2,500 \mathrm{x} \mathrm{g}, 4^{\circ} \mathrm{C}\right)$ for $10 \mathrm{~min}$ and the samples were frozen at $-80^{\circ} \mathrm{C}$. Further, another 2-hours postprandial (after meal) venous blood sample $(2.0 \mathrm{ml})$ was taken and centrifuged as above. Urine samples $(10-15 \mathrm{ml})$ of each patient were collected with plugged tubes and stored at $2-8^{\circ} \mathrm{C}$ for further usage.

Therapeutic regimens. Two groups of patients were given routine diabetic diet management (to ensure balance and optimal nutrition of carbohydrates, protein and fat for the daily needs of human body) and oral hypoglycemic agents and/or insulin to control blood glucose within the range of ideal level (FBG $<8.0 \mathrm{mmol} / 1$, postprandial blood glucose $<10.0 \mathrm{mmol} / \mathrm{l}$ ). Subjects in the $\mathrm{T}$ group (telmisartan group) were given oral telmisartan (Zhejiang Tailison Pharmaceutical Co. Ltd., Jiaxing, China; batch no. H20140032, specifications: $40 \mathrm{mg} /$ tablet) at a dose of $40 \mathrm{mg}$ daily for 4 weeks. Patients in the $\mathrm{S}+\mathrm{T}$ group (Salvia miltiorrhiza injection + telmisartan) were administered with preprandial Salvia miltiorrhiza intravenous injection by the patients themselves combined with the administration of telmisartan, and the use of telmisartan was the same as in the T group, at a dose of $40 \mathrm{mg}$ per day for 4 weeks. Salvia miltiorrhiza injection was offered by a local pharmaceutical company (China Pharmaceutical University Pharmaceutical Co. Ltd., Nanjing, China; batch no. Z32020678, specifications: $10 \mathrm{ml} /$ branch). Patients in the $\mathrm{S}+\mathrm{T}$ group were treated by intravenous drip of $20 \mathrm{ml}$ Salvia miltiorrhiza injection with $250 \mathrm{ml}$ physiological saline injection once daily, in a total of 4 weeks of continuous medication.

Main outcome measures. Glucose level in the serum of incorporated patients were compared in the 1st week, 2nd week and 4th week after treatment. The measurement of FBG, 2h PBG, and $\mathrm{HbAlc}$ was conducted with a biochemical analyzer (Beckman-700, Beckman Coulter, Inc., Fullerton, CA, USA). Blood pressure (systolic blood pressure and diastolic blood pressure) monitoring was based on a standard mercury sphygmomanometer on the right arm of each patient. Measurements were usually taken by the same investigator of the same item. Furthermore, a comparison of renal function indexes was performed before and after treatment (1st week, 2nd week and 4th week). Scr and BUN levels were examined by using full automatic biochemical analyzer (Beckman-700, Beckman Coulter, Inc.). The levels of UAER was detected in $24 \mathrm{~h}$ urine samples by radioimmunoassay.

In addition, the levels of ColIV and FN in urine samples of patients were examined before treatment and in the 1st week, 2nd week and 4th week after treatment. Urine ColIV and FN levels were detected by enzyme-linked immunosorbent assay (ELISA) kit. Due to the low concentration of ColIV in urine, collected samples was concentrated and then tested. The concentration processing was as follows: $10 \mathrm{~g} / \mathrm{l}$ bovine
Table I. Comparison of baseline characteristics between the case group and the control group.

\begin{tabular}{lcc}
\hline Variables & $\begin{array}{c}\text { Case group } \\
(\mathrm{n}=258)\end{array}$ & $\begin{array}{c}\text { Control group } \\
(\mathrm{n}=110)\end{array}$ \\
\hline Sex (Male/ Female) & $140 / 118$ & $52 / 58$ \\
Age (years) & $52.00 \pm 3.39$ & $50.00 \pm 2.87$ \\
Disease duration (years) & $5.70 \pm 1.23$ & \\
SBP (mmHg) & $140.00 \pm 15.00$ & $134.00 \pm 12.00$ \\
DBP $(\mathrm{mmHg})$ & $85.00 \pm 10.00$ & $82.00 \pm 9.00$ \\
TC $(\mathrm{mmol} / \mathrm{l})$ & $4.44 \pm 0.41$ & $4.23 \pm 0.61$ \\
TG $(\mathrm{mmol} / \mathrm{l})$ & $1.16 \pm 0.13$ & $1.01 \pm 0.12$ \\
HDL-C (mmol/l) & $1.42 \pm 0.13$ & $1.14 \pm 0.14$ \\
LDL-C (mmol/l) & $2.42 \pm 0.46$ & $2.22 \pm 0.38$ \\
VLDL-C (mmol/l) & $0.96 \pm 0.18$ & $0.85 \pm 0.14$ \\
FBG & $8.04 \pm 0.72$ & $6.29 \pm 1.02$ \\
2h PBG & $12.09 \pm 1.40$ & $8.27 \pm 0.79$ \\
HbA1c & $10.49 \pm 1.53$ & $8.22 \pm 1.46$ \\
BUN (mmol/l) & $9.83 \pm 2.99$ & $9.31 \pm 1.90$ \\
Scr $(\mu \mathrm{mol} / \mathrm{l})$ & $109.74 \pm 8.77$ & $79.50 \pm 3.46$ \\
UAER & $126.73 \pm 11.14$ & $20.05 \pm 1.31$ \\
& &
\end{tabular}

SBP, systolic blood pressure; DBP, diastolic blood pressure; TC, total cholesterol; TG, triglycide; HDL-C, high density lipoprotein cholesterol; LDL-C, low density lipoprotein cholesterol; VLDL-C, very low density lipoprotein cholesterol; FBG, fasting blood glucose; 2h PBG, $2 \mathrm{~h}$ post-prandial blood glucose; HbA1c, glycosylated hemoglobin; BUN, blood urea nitrogen; Scr, serum creatinine; UAER, urinary albumin excretion rate.

$\gamma$-globulin $(0.8 \mathrm{ml})$ and $450 \mathrm{~g} / 1 \mathrm{PEG}-4000(5 \mathrm{ml})$ were added in the $10 \mathrm{ml}$ urine specimens in turn, and the prepared specimens were mixed subsequently. Followed by centrifugation at $1,500 \mathrm{x} \mathrm{g}$ for $30 \mathrm{~min}$ at $4^{\circ} \mathrm{C}$, the supernatant was removed, and samples were dissolved in $1 \mathrm{ml}$ of physiological saline to achieve 10-fold concentration. The absorbance (A) [optical density (OD)] value was determined in dual wavelength mode $(450 \mathrm{~nm})$ with a calibration wavelength of $570 \mathrm{~nm}$ by full wavelength spectrophotometer (Hitachi, Ltd., Tokyo, Japan). Using OD value as a vertical coordinate, the standard product concentration as the horizontal coordinate, the standard curve was drawn and the urine ColIV and FN levels were calculated accordingly. The test was repeated three times to ensure the repeatability of the experiment.

Adverse events. Adverse drug reaction was defined as adverse consequences of drug therapy in the course of treatment (30). Adverse events of patients in each drug intervention groups of $\mathrm{T}$ group and $\mathrm{S}+\mathrm{T}$ group were observed in an observation period of 6 months, and the incidence rate of adverse reaction was recorded simultaneously. Observed adverse drug reaction included dyslipidemia, nausea and headache, dizziness, fatigue, ankle oedema, constipation, gastrointestinal reaction, hyperphosphatemia, hypercalcemia and hypotension $(31,32)$. Various adverse events unrelated to the purpose of the treatment were carefully recorded in the target patients, including the extent, duration, requirement for special handling and 
Table II. Comparison results of glycemic indexes and renal damage indexes between the control group and the case group, within different intervention groups.

\begin{tabular}{|c|c|c|c|c|}
\hline \multirow[b]{2}{*}{ Variables } & \multirow[b]{2}{*}{$\begin{array}{l}\text { Control group } \\
(\mathrm{n}=110)\end{array}$} & \multicolumn{3}{|c|}{ Case group } \\
\hline & & $\begin{array}{l}\text { Placebo group } \\
\quad(\mathrm{n}=86)\end{array}$ & $\begin{array}{l}\text { T group } \\
(\mathrm{n}=86)\end{array}$ & $\begin{array}{c}S+T \text { group } \\
(n=86)\end{array}$ \\
\hline FBG & $6.18 \pm 1.98$ & $7.80 \pm 1.49^{\mathrm{a}}$ & $8.36 \pm 2.64^{\mathrm{a}}$ & $7.96 \pm 2.20^{\mathrm{a}}$ \\
\hline $2 \mathrm{~h} \mathrm{PBG}$ & $8.56 \pm 2.04$ & $13.17 \pm 1.10^{\mathrm{a}}$ & $11.75 \pm 2.45^{\mathrm{a}}$ & $11.63 \pm 1.15^{\mathrm{a}}$ \\
\hline $\mathrm{HbA1c}$ & $7.56 \pm 1.76$ & $11.00 \pm 2.35^{\mathrm{a}}$ & $10.93 \pm 2.96^{\mathrm{a}}$ & $11.62 \pm 1.91^{\mathrm{a}}$ \\
\hline BUN (mmol/l) & $9.25 \pm 1.88$ & $10.12 \pm 4.02^{\mathrm{a}}$ & $11.81 \pm 2.92^{\mathrm{a}}$ & $11.83 \pm 3.78^{\mathrm{a}, \mathrm{b}}$ \\
\hline $\operatorname{Scr}(\mu \mathrm{mol} / \mathrm{l})$ & $81.05 \pm 8.49$ & $117.21 \pm 7.61^{\mathrm{a}}$ & $113.65 \pm 6.25^{\mathrm{a}}$ & $119.64 \pm 7.17^{\mathrm{a}}$ \\
\hline UAER & $20.04 \pm 2.67$ & $120.00 \pm 19.94^{\mathrm{a}}$ & $129.16 \pm 15.17^{\mathrm{a}}$ & $127.46 \pm 17.38^{a, b}$ \\
\hline ColIV & $165.40 \pm 10.59$ & $193.61 \pm 28.16^{\mathrm{a}}$ & $186.04 \pm 24.37^{\mathrm{a}}$ & $195.44 \pm 23.65^{\mathrm{a}, \mathrm{b}}$ \\
\hline FN & $69.04 \pm 9.64$ & $102.55 \pm 13.67^{\mathrm{a}}$ & $95.95 \pm 12.12^{\mathrm{a}, \mathrm{b}}$ & $95.56 \pm 18.58^{a, b}$ \\
\hline
\end{tabular}

FBG, fasting blood glucose; 2h PBG, 2 h post-prandial blood glucose; HbA1c, glycosylated hemoglobin; BUN, blood urea nitrogen; Scr, serum creatinine; UAER, urinary albumin excretion rate; ColIV, collagen IV; FN, fibronectin. ${ }^{\mathrm{a}} \mathrm{P}<0.05$, comparing target parameters between the control group and the case group, including the placebo group (with no drugs intervention, just placebo therapy), the T group (telmisartan group, given oral telmisartan administration), the $\mathrm{S}+\mathrm{T}$ group (Salvia miltiorrhiza injection + telmisartan, administered with Salvia miltiorrhiza injection combined with telmisartan treatment); ${ }^{\mathrm{b}} \mathrm{P}<0.05$, comparing target parameters between the placebo group and the $\mathrm{T}$ group and the $\mathrm{S}+\mathrm{T}$ group, respectively.

the clinical outcome. All the adverse events and therapeutic regimens were analyzed according to the following five items, namely, 'affirmation', 'probably', 'may', 'suspicious' and 'impossible' (33) and the first three items were predefined as drug adverse reactions. Adverse drug reaction and corresponding rates were then compared between groups.

Statistical analysis. Using SPSS 22.0 statistical software (IBM Corp., Armonk, NY, USA), measurement data were presented as mean \pm standard deviation. To compare continuous variables with normal distribution, we used student's t-test or analysis of variance (ANOVA), followed by post hoc test (Least Significant Difference), for multiple group comparisons. Bilateral $\mathrm{P}<0.05$ was statistically significant

\section{Results}

Basic information comparison among groups. As shown in Table I, there were 258 cases included in the case group (male/female: 140/118), all of whom were diagnosed with stage IV DN, with a mean age of $52.00 \pm 3.39$ years. Further, in the control group, there were 110 cases of subjects, including 52 males and 58 females, with a mean age of $50.00 \pm 2.87$ years. No differences in age and sex were found between groups (both $\mathrm{P}>0.05$ ), suggesting comparability between groups. In addition, duration of disease in the case group was $5.70 \pm 1.23$ years; further, in the case group, after being divided into the three case groups (the placebo group, the $\mathrm{T}$ group, and the $\mathrm{S}+\mathrm{T}$ group) randomly and equally, there were 86 cases in each group.

Comparison of glycemic indexes and renal damage indexes. Table II shows the comparison results of glycemic indexes and renal damage indexes between the control group and the case group, as well as within different intervention groups. Firstly, in the comparison between the case group and the control group, parameters all showed significantly increased trends in the case groups, with statistically differences (all $\mathrm{P}<0.05$ ).

Furthermore, as presented in Table II, comparison within the intervention groups revealed that there were statistical differences with respect to correlated levels after intervention (all $\mathrm{P}<0.05$ ), all indicated downwards trends both in the $\mathrm{T}$ group and in the $\mathrm{S}+\mathrm{T}$ group when compared to the placebo group; besides, levels in the $\mathrm{S}+\mathrm{T}$ group were much lower than those in the T group. In comparison, there were statistical significance regarding levels of BUN and UAER between the placebo group and the $\mathrm{S}+\mathrm{T}$ group. Furthermore, as shown in Table III, difference in the FBG, 2h PBG, HbAlc, BUN, Scr and UAER were shown to be significant at different timepoints after treatment when compared to the levels before treatment in the $\mathrm{T}$ group. There were signifcant differences in the comparison of the above-mentioned glycemic indexes at different time-points after treatment than those before treatment for $\mathrm{S}+\mathrm{T}$ group, which are presented in Table IV. Furthermore, the majority of the detected parameters were significantly decreased in the comparison of the 1st week after treatment with the 2nd and 4th week, and in the comparison between the 2 nd week and the 4 th week, showing statistical difference (all $\mathrm{P}<0.05$ ).

CollV and FN levels at different time periods after treatment. As listed in Table II, it was detected that before intervention, both the levels of ColIV and FN in the urine were all increased evidently in the case groups compared to the control group, showing statistical difference (both $\mathrm{P}<0.05$ ). Besides, within the case groups, urine FN level was decreased in the T group and the $\mathrm{S}+\mathrm{T}$ group when compared with the placebo group, showing statistical differences (all $\mathrm{P}<0.05$ ); yet none obvious statistical difference was found in ColIV that requires further identification with larger sample size. 
Table III. Comparison of results of glycemic indexes and renal damage indexes within telmisartan group with oral telmisartan administration at different time-points after treatment.

\begin{tabular}{|c|c|c|c|c|}
\hline Variables & Before treatment & $\begin{array}{c}1 \text { week } \\
\text { after treatment }\end{array}$ & $\begin{array}{c}2 \text { weeks } \\
\text { after treatment }\end{array}$ & $\begin{array}{c}4 \text { weeks } \\
\text { after treatment }\end{array}$ \\
\hline FBG & $8.36 \pm 2.64$ & $7.96 \pm 1.58$ & $8.41 \pm 1.11^{\mathrm{a}, \mathrm{b}}$ & $7.49 \pm 0.97^{\mathrm{a}, \mathrm{b}, \mathrm{c}}$ \\
\hline $2 \mathrm{~h}$ PBG & $11.75 \pm 2.45$ & $9.41 \pm 1.69^{\mathrm{a}}$ & $10.75 \pm 1.74^{\mathrm{a}, \mathrm{b}}$ & $8.03 \pm 1.64^{\mathrm{a}, \mathrm{b}, \mathrm{c}}$ \\
\hline HbA1c & $10.93 \pm 2.96$ & $10.68 \pm 1.48$ & $11.26 \pm 2.33^{\mathrm{a}}$ & $8.91 \pm 0.94^{\mathrm{a}, \mathrm{b}, \mathrm{c}}$ \\
\hline BUN (mmol/l) & $11.81 \pm 2.92$ & $10.64 \pm 1.63^{a}$ & $9.06 \pm 1.27^{\mathrm{a}, \mathrm{b}}$ & $8.43 \pm 2.13^{\mathrm{a}, \mathrm{b}, \mathrm{c}}$ \\
\hline $\operatorname{Scr}(\mu \mathrm{mol} / \mathrm{l})$ & $113.65 \pm 6.25$ & $103.69 \pm 9.88^{\mathrm{a}}$ & $89.62 \pm 6.95^{\mathrm{a}, \mathrm{b}}$ & $79.99 \pm 6.62^{a, b, c}$ \\
\hline UAER & $129.16 \pm 15.17$ & $117.41 \pm 15.89^{\mathrm{a}}$ & $71.92 \pm 7.63^{\mathrm{a}, \mathrm{b}}$ & $103.36 \pm 8.47^{\mathrm{a}, \mathrm{b}, \mathrm{c}}$ \\
\hline ColIV & $186.04 \pm 24.37$ & $168.86 \pm 15.47^{\mathrm{a}}$ & $160.44 \pm 18.58^{\mathrm{a}, \mathrm{b}}$ & $156.69 \pm 10.39^{\mathrm{a}, \mathrm{b}}$ \\
\hline $\mathrm{FN}$ & $95.95 \pm 12.12$ & $91.78 \pm 7.79^{a}$ & $83.56 \pm 7.73^{\mathrm{a}, \mathrm{b}}$ & $77.03 \pm 7.73^{\mathrm{a}, \mathrm{b}, \mathrm{c}}$ \\
\hline
\end{tabular}

FBG, fasting blood glucose; 2h PBG, 2 h post-prandial blood glucose; HbA1c, glycosylated hemoglobin; BUN, blood urea nitrogen; Scr, serum creatinine; UAER, urinary albumin excretion rate; ColIV, collagen IV; FN, fibronectin. ${ }^{\mathrm{a}} \mathrm{P}<0.05$, comparing target parameters at different time-points before treatment and after treatment; ${ }^{b} \mathrm{P}<0.05$, comparing target parameters at different time-points after treatment, including the comparison between the first week and the second/fourth week, respectively; ${ }^{\mathrm{C}} \mathrm{P}<0.05$, comparing target parameters at different time-points between the second week and the fourth week.

Table IV. Comparison of results of glycemic indexes and renal damage indexes within Salvia miltiorrhiza injection + telmisartan group administered with Salvia miltiorrhiza injection combined with telmisartan treatment at different time-points after treatment.

\begin{tabular}{|c|c|c|c|c|}
\hline Variables & Before treatment & $\begin{array}{c}1 \text { week } \\
\text { after treatment }\end{array}$ & $\begin{array}{l}2 \text { weeks } \\
\text { after treatment }\end{array}$ & $\begin{array}{c}4 \text { weeks } \\
\text { after treatment }\end{array}$ \\
\hline FBG & $7.96 \pm 2.20$ & $7.39 \pm 1.62^{\mathrm{a}}$ & $6.19 \pm 1.36^{\mathrm{a}, \mathrm{b}}$ & $6.22 \pm 1.12^{\mathrm{a}, \mathrm{b}}$ \\
\hline 2 h PBG & $11.63 \pm 1.15$ & $11.73 \pm 2.74$ & $8.55 \pm 1.58^{\mathrm{a}, \mathrm{b}}$ & $7.98 \pm 1.15^{\mathrm{a}, \mathrm{b}, \mathrm{c}}$ \\
\hline $\mathrm{HbA1c}$ & $11.62 \pm 1.91$ & $10.10 \pm 2.56$ & $10.35 \pm 2.47$ & $8.34 \pm 1.14^{\mathrm{a}, \mathrm{b}, \mathrm{c}}$ \\
\hline BUN (mmol/l) & $11.83 \pm 3.78$ & $9.97 \pm 2.11$ & $9.64 \pm 2.46$ & $7.76 \pm 3.05^{\mathrm{a}, \mathrm{b}, \mathrm{c}}$ \\
\hline $\operatorname{Scr}(\mu \mathrm{mol} / \mathrm{l})$ & $119.64 \pm 7.17$ & $112.13 \pm 8.89$ & $99.05 \pm 7.49^{\mathrm{a}, \mathrm{b}}$ & $81.94 \pm 5.37^{\mathrm{a}, \mathrm{b}, \mathrm{c}}$ \\
\hline UAER & $127.46 \pm 17.38$ & $108.15 \pm 10.43^{\mathrm{a}}$ & $93.28 \pm 7.84^{\mathrm{a}, \mathrm{b}}$ & $66.38 \pm 10.02^{\mathrm{a}, \mathrm{b}, \mathrm{c}}$ \\
\hline ColIV & $195.44 \pm 23.65$ & $171.21 \pm 24.28^{\mathrm{a}}$ & $177.40 \pm 29.07^{\mathrm{a}}$ & $164.44 \pm 21.01^{\mathrm{a}, \mathrm{c}}$ \\
\hline FN & $95.56 \pm 18.58$ & $79.71 \pm 17.24^{\mathrm{a}}$ & $72.09 \pm 11.19^{\mathrm{a}, \mathrm{b}}$ & $61.16 \pm 10.54^{a, b, c}$ \\
\hline
\end{tabular}

FBG, fasting blood glucose; 2h PBG, 2 h post-prandial blood glucose; HbA1c, glycosylated hemoglobin; BUN, blood urea nitrogen; Scr, serum creatinine; UAER, urinary albumin excretion rate; ColIV, collagen IV; FN, fibronectin. ${ }^{\mathrm{a}} \mathrm{P}<0.05$, comparing target parameters at different time-points before treatment and after treatment; ${ }^{b} \mathrm{P}<0.05$, comparing target parameters at different time-points after treatment, including the comparison between the first week and the second/fourth week, respectively; ${ }^{\mathrm{C}} \mathrm{P}<0.05$, comparing target parameters at different time-points between the second week and the fourth week.

In addition, after intervention by Salvia miltiorrhiza injection and telmisartan, both Co1IV and FN levels were apparently decreased, especially in the $\mathrm{S}+\mathrm{T}$ group, with statistical difference $(\mathrm{P}<0.05)$. Differences in the levels of ColIV and FN were shown to be significant at different time-points after treatment in the $\mathrm{T}$ group and in the $\mathrm{S}+\mathrm{T}$ group (Tables III and IV, respectively). To be specific, there were statistical differences in that both urine levels of Co1IV and FN were significantly decreased comparing data before and after treatment at different time-points of the 1st week, 2nd week and 4th week (all $\mathrm{P}<0.05$ ). Statistical differences were also found in levels of ColIV and FN in the urine indicated by decreased tendency at the 2 nd and 4 th week when compared to the 1 st week (all $\mathrm{P}<0.05$ ). Importantly, results indicated that there were significantly positive correlations of ColIV and FN with FBG, 2h PBG, HbAlc, BUN, Scr and UAER, corresponding differences were significant (all $\mathrm{P}<0.05$ ).

Comparison of adverse drug reaction. During the observation period of 6 months, there were 5 cases of dyslipidemia, 7 cases of fatigue, 4 cases of nausea and headache, 2 cases of constipation and dizziness, respectively in the $\mathrm{T}$ group, and the rate of adverse drug reaction was $20.93 \%$. Furthermore, in the $\mathrm{S}+\mathrm{T}$ group, there were 3 cases of dyslipidemia, 4 cases of fatigue, 2 cases of constipation, 2 cases of nausea and headache, and corresponding adverse drug reaction rate was $12.79 \%$. No other adverse drug reaction was found in either group. The statistical difference of adverse drug reaction was 
much lower in the $\mathrm{S}+\mathrm{T}$ group compared to that in the $\mathrm{T}$ group $(\mathrm{P}<0.05)$.

\section{Discussion}

$\mathrm{DN}$ is one of the common and severe microvascular complications of diabetes, and end-stage renal disease caused by DN has become a major cause in chronic renal failure (34). At present, the pathogenesis of DN has not been fully elucidated, and previous studies focused on the exploration of lipid metabolism, oxidative stress, hemodynamics, vasoactive substances and genetic susceptibility (35-37). In general, DN is characterized by glomerular and tubular structural changes, including the following pathological features, such as the thickening of glomerular and tubular basement membrane, the expansion of mesangial matrix, and the occurrence of renal interstitial fibrosis. Besides, typical clinical pathological features are the accumulation of glomerular basement membrane and renal tubular basement membrane, as well as the ECM accumulation in mesangial cells, which eventually contribute to the occurrence of diffuse and nodular glomerulosclerosis $(38,39)$.

Statistical analysis of the present study indicated that urine levels of ColIV and FN were significantly higher in DN patients compared to normal controls; further results suggested that there were obvious positive correlations of ColIV and FN with the levels of FBG, 2h PBG, HbAlc, BUN, Scr and UAER. The change of Scr concentration is mainly determined by the glomerular filtration rate, and the increased concentration of Scr usually indicates a decreased filtration capacity and thus correlated with a damage in the kidney accurately. Besides, both BUN and UAER are common and accurate parameters for the evaluation of renal impairment. Those results indicated that increased levels of ColIV and FN in the urine might indicate the progression of glomerular and tubular dysfunction, and correlated obviously with blood glucose levels changes. Higher PBG, HbA1c levels indicated the more severe and longer glucose toxicity on the kidney, suggesting the importance and necessity of $2 \mathrm{~h}$ PBG and HbAlc regulation in the prevention and treatment of $\mathrm{DN}$.

After intervention treatment, the majority of blood glucose correlated parameters and renal damage indexes all showed obvious decreased trends along with the time of treatment when compared to the DN patients without intervention, suggesting that both the treatment of Salvia miltiorrhiza injection and telmisartan might have positive effect in decreasing blood glucose and retarding kidney damage. Furthermore, such positive effect was much more obvious in the subgroup managed by Salvia miltiorrhiza injection with telmisartan than treated by telmisartan alone, highlighting that there might be certain synergistic effect of both drugs. It should be noted that both levels of ColIV and FN in urine indicated evidently decreased tendency in the targeted patients, we therefore speculated that Salvia miltiorrhiza injection with telmisartan have beneficial treatment effect for patients with DN through attenuating the increase in ColIV and FN, inversing the increased levels of FBG, $2 \mathrm{~h}$ PBG, HbAlc, BUN, Scr and UAER, and thus postponing or reversing the changes of the ultrastructure of glomerular basement membrane. Meanwhile, in our study, relevant adverse drug reactions were reported in patients under intervention, such as dyslipidemia, fatigue, nausea and headache, constipation and dizziness, and the observed rate of adverse drug reaction was much lower in the $\mathrm{S}+\mathrm{T}$ group than compared to that in the $\mathrm{T}$ group, which might suggested that the combination of Salvia miltiorrhiza injection and telmisartan would be superior to single application of telmisartan for DN patients, combined with relatively lower adverse drug reaction. Importantly, all recorded adverse drug reactions were of mild nature that did not influence the continuity of treatment in the study, suggesting the efficacy and feasibility of both therapies in the treatment of DN.

Generally speaking, the glomerular is the filtering device of the kidney, and mesangial cells and ECM support the capillary network of glomerular (40). DN is found to be caused by excessive accumulation of ECM, especially the deposition of ColIV, which is the result of the damage of glomerular function and eventually leading to renal fibrosis (41). Secreted by endothelial cells and epithelial cells of special membrane protein, ColIV is the main chemical composition of the basement membrane; its abnormal synthesis and degradation correlate significantly with the development of DN $(42,43)$. As for FN, it is an important component of ECM, and high expression of FN can be detected in the glomerular mesangial region, as well as in the renal tubule $(44,45)$. Excessive accumulation of FN in glomerular and tubular cells may be the main reason for the declined kidney function (46). In this study, before intervention, there were more positive increases of ColIV and FN in the DN patients than compared to the normal healthy controls. We therefore postulated that under hyperglycemic state, ColIV and FN were both increased in synthesis and decreased in degradation, resulting in excessive accumulation of ECM, critical in the damage of renal function and further renal fibrosis. After telmisartan treatment alone or combined with Salvia miltiorrhiza injection, downward trends of the detected parameters were found in the intervened subjects when compared with those without treatment, and the hyperglycemic state was reversed, indicating that Salvia miltiorrhiza injection with telmisartan might be effective in suppressing the expression and syntheses of ColIV and FN in the kidney. Possible functionary mechanism may be correlated with the reason that the major component of Salvia miltiorrhiza injection is tanshinone, which can improve the microcirculation of the human body and renal blood flow by eliminating free radicals and decreasing lipid peroxidation reaction $(47,48)$. Besides, telmisartan instead of angiotensin II receptor can indicate high affinity binding of AT1 receptor subtype, and the combination action may be persistently effective for lowering blood pressure (49).

However, there were some limitations that should be taken into account in the study. The primary limitation was the relatively small sample size and short observation duration. Insufficient samples might always result in unstable index detection that might affect the overall accuracy, and some results with statistical differences were difficult to reflect. In addition, relatively short observation duration, especially for therapeutic effects evaluation, might result in an underestimation of risk or effect; longer period of observation would be better for more comprehensive assessment of the clinical data. Future studies should be performed on the basis of larger sample size and longer observation duration to evaluate the curative effect and safety of Salvia miltiorrhiza injection and 
telmisartan. Secondly, further studies are recommended to assess the significance of dose-dependent and time-dependent drugs in the treatment of different stages of DN. Generally, accurate dosage and time control can bring the effect of drugs into full play to reduce adverse effect and prolong effect time. Therefore, further studies in vivo and in vitro are recommended to investigate the value of dose-dependent and time-dependent manner of the present drugs for DN patients in a larger sample size population within longer period of observation.

In conclusion, increased ColIV and FN levels may be partially responsible for the development of $\mathrm{DN}$, associated significantly with the hyperglycemia state and ultrastructure changes of the glomerular basement membranes. Salvia miltiorrhiza injection with telmisartan have beneficial synergistic effect and lower adverse drug reaction for DN patients through attenuating the increase in ColIV and FN, inversing hyperglycemia state and postponing ultrastructure changes of glomerular basement membrane.

\section{Acknowledgements}

Not applicable.

\section{Funding}

No funding was received.

\section{Availability of data and materials}

The datasets used and/or analyzed during the present study are available from the corresponding author on reasonable request.

\section{Authors' contributions}

JMN analyzed and interpreted the patient data, and was a major contributor in writing the manuscript. HFL performed the experiments and participated in the design of the study. Both authors read and approved the final manuscript.

\section{Ethics approval and consent to participate}

This study was approved by the Ethics Committee of the Third Affiliated Hospital of Guangzhou Medical University (Guangzhou, China). Signed informed consents were obtained from the patients or the guardians.

\section{Patient consent for publication}

Not applicable.

\section{Competing interests}

The authors declare that they have no competing interests.

\section{References}

1. Crossland L, Askew D, Ware R, Cranstoun P, Mitchell P, Bryett A and Jackson C: Diabetic retinopathy screening and monitoring of early stage disease in Australian general practice: Tackling preventable blindness within a chronic care model. J Diabetes Res 2016: 8405395, 2016.
2. Cobas RA, Santos B, da Silva PC, Neves R and Gomes MB Progression to microalbuminuria in patients with type 1 diabetes: A seven-year prospective study. Diabetol Metab Syndr 3: 21, 2011.

3. Reutens AT and Atkins RC: Epidemiology of diabetic nephropathy. Contrib Nephrol 170: 1-7, 2011.

4. Van Buren PN and Toto R: Hypertension in diabetic nephropathy: Epidemiology, mechanisms, and management. Adv Chronic Kidney Dis 18: 28-41, 2011.

5. Navarro-González JF and Mora-Fernández C: The role of inflammatory cytokines in diabetic nephropathy. J Am Soc Nephrol 19 433-442, 2008

6. Zhou Z, Pausch F, Schlötzer-Schrehardt U, Brachvogel B and Pöschl E: Induction of initial steps of angiogenic differentiation and maturation of endothelial cells by pericytes in vitro and the role of collagen IV. Histochem Cell Biol 145: 511-525, 2016.

7. Behrens DT, Villone D, Koch M, Brunner G, Sorokin L, Robenek H, Bruckner-Tuderman L, Bruckner P and Hansen U: The epidermal basement membrane is a composite of separate laminin- or collagen IV-containing networks connected by aggregated perlecan, but not by nidogens. J Biol Chem 287: 18700-18709, 2012.

8. Rosado C, Bueno E, Fraile P, García-Cosmes P and GonzálezSarmiento R: A new mutation in the COL4A3 gene responsible for autosomal dominant Alport syndrome, which only generates hearing loss in some carriers. Eur J Med Genet 58: 35-38, 2015.

9. Yoneda Y, Haginoya K, Arai H, Yamaoka S, Tsurusaki Y, Doi H Miyake N, Yokochi K, Osaka H, Kato M, et al: De novo and inherited mutations in COL4A2, encoding the type IV collagen $\alpha 2$ chain cause porencephaly. Am J Hum Genet 90: 86-90, 2012.

10. El-Mezayen HA, Habib S, Marzok HF and Saad MH: Diagnostic performance of collagen IV and laminin for the prediction of fibrosis and cirrhosis in chronic hepatitis $\mathrm{C}$ patients: A multicenter study. Eur J Gastroenterol Hepatol 27: 378-385, 2015.

11. Abrahamson DR, St John PL, Stroganova L, Zelenchuk A and Steenhard BM: Laminin and type IV collagen isoform substitutions occur in temporally and spatially distinct patterns in developing kidney glomerular basement membranes. J Histochem Cytochem 61: 706-718, 2013.

12. Ruggiero S, Cosgarea R, Potempa J, Potempa B, Eick S and Chiquet M: Cleavage of extracellular matrix in periodontitis: Gingipains differentially affect cell adhesion activities of fibronectin and tenascin-C. Biochim Biophys Acta 1832: 517-526, 2013.

13. Halper J and Kjaer M: Basic components of connective tissues and extracellular matrix: Elastin, fibrillin, fibulins, fibrinogen, fibronectin, laminin, tenascins and thrombospondins. Adv Exp Med Biol 802: 31-47, 2014.

14. Kang Y, Georgiou AI, MacFarlane RJ, Klontzas ME, Heliotis M, Tsiridis E and Mantalaris A: Fibronectin stimulates the osteogenic differentiation of murine embryonic stem cells. J Tissue Eng Regen Med 11: 1929-1940, 2017.

15. Sawicka KM, Seeliger M, Musaev T, Macri LK and Clark RA Fibronectin interaction and enhancement of growth factors: Importance for wound healing. Adv Wound Care (New Rochelle) 4: 469-478, 2015.

16. Linsley C, Wu B and Tawil B: The effect of fibrinogen, collagen type I, and fibronectin on mesenchymal stem cell growth and differentiation into osteoblasts. Tissue Eng Part A 19: 1416-1423, 2013.

17. Kenny HA, Chiang CY, White EA, Schryver EM, Habis M, Romero IL, Ladanyi A, Penicka CV, George J, Matlin K, et al: Mesothelial cells promote early ovarian cancer metastasis through fibronectin secretion. J Clin Invest 124: 4614-4628, 2014.

18. Mòdol T, Brice N, Ruiz de Galarreta M, García Garzón A, Iraburu MJ, Martínez-Irujo JJ and López-Zabalza MJ: Fibronectin peptides as potential regulators of hepatic fibrosis through apoptosis of hepatic stellate cells. J Cell Physiol 230: 546-553, 2015.

19. Toledo E, Hu FB, Estruch R, Buil-Cosiales P, Corella D, SalasSalvadó J, Covas MI, Arós F, Gómez-Gracia E, Fiol M, et al: Effect of the Mediterranean diet on blood pressure in the PREDIMED trial: Results from a randomized controlled trial. BMC Med 11: 207, 2013.

20. Xiong X, Yang X, Liu W, Chu F, Wang P and Wang J: Trends in the treatment of hypertension from the perspective of traditional Chinese medicine. Evid Based Complement Alternat Med 2013: 275279, 2013.

21. Ebner T, Schänzle G, Weber W, Sent U and Elliott J: In vitro glucuronidation of the angiotensin II receptor antagonist telmisartan in the cat: A comparison with other species. J Vet Pharmacol Ther 36: 154-160, 2013. 
22. Podymow T and Joseph G: Preconception and pregnancy management of women with diabetic nephropathy on angiotensin converting enzyme inhibitors. Clin Nephrol 83: 73-79, 2015.

23. Lewis G and Maxwell AP: Should women with diabetic nephropathy considering pregnancy continue ACE inhibitor or angiotensin II receptor blocker therapy until pregnancy is confirmed? Diabetologia 57: 1082-1083, 2014.

24. van Poppel PC, Breedveld P, Abbink EJ, Roelofs H, van Heerde W, Smits P, Lin W, Tan AH, Russel FG, Donders R, et al: Salvia miltiorrhiza root water-extract (Danshen) has no beneficial effect on cardiovascular risk factors. A randomized double-blind cross-over trial. PLoS One 10: e0128695, 2015.

25. Zhou X, Chan K and Yeung JH: Herb-drug interactions with Danshen (Salvia miltiorrhiza): A review on the role of cytochrome P450 enzymes. Drug Metabol Drug Interact 27: 9-18, 2012.

26. Liu Y, Huang Y, Zhao C, Qin X, Zhu Q, Chen S and Qu J: Salvia miltiorrhiza injection on pulmonary heart disease: A systematic review and meta-analysis. Am J Chin Med 42: 1315-1331, 2014.

27. Luo J, Song W, Yang G, Xu H and Chen K: Compound Danshen (Salvia miltiorrhiza) dripping pill for coronary heart disease: An overview of systematic reviews. Am J Chin Med 43: 25-43, 2015.

28. Ge G, Zhang Q, Ma J, Qiao Z, Huang J, Cheng W and Wang H: Protective effect of Salvia miltiorrhiza aqueous extract on myocardium oxidative injury in ischemic-reperfusion rats. Gene 546: 97-103, 2014

29. Mogensen C: Early diabetic renal involvement and nephropathy. Diabetes Annual 3: 306-324, 1987.

30. Upadhyaya HB, Vora MB, Nagar JG and Patel PB: Knowledge, attitude and practices toward pharmacovigilance and adverse drug reactions in postgraduate students of Tertiary Care Hospital in Gujarat. J Adv Pharm Technol Res 6: 29-34, 2015.

31. Goyal J, Khan ZY, Upadhyaya P, Goyal B and Jain S: Comparative study of high dose mono-therapy of amlodipine or telmisartan, and their low dose combination in mild to moderate hypertension. J Clin Diagn Res 8: HC08-HC11, 2014.

32. Huang JZ, Zheng FS and Yang Y: Clinical observation of telmisartan combined with tongxinluo capsules in the treatment of early diabetic nephropathy. China Pharm 22: 1101-1103, 2011.

33. Sato-Horiguchi C, Ogawa D, Wada J, Tachibana H, Kodera R, Eguchi J, Nakatsuka A, Terami N, Shikata K and Makino H: Telmisartan attenuates diabetic nephropathy by suppressing oxidative stress in db/db mice. Nephron Exp Nephrol 121: e97-e108, 2012.

34. Bjornstad P, Snell-Bergeon JK, Rewers M, Jalal D, Chonchol MB Johnson RJ and Maahs DM: Early diabetic nephropathy: A complication of reduced insulin sensitivity in type 1 diabetes. Diabetes Care 36: 3678-3683, 2013

35. Kim BH, Lee ES, Choi R, Nawaboot J, Lee MY, Lee EY, Kim HS and Chung $\mathrm{CH}$ : Protective effects of curcumin on renal oxidative stress and lipid metabolism in a rat model of type 2 diabetic nephropathy. Yonsei Med J 57: 664-673, 2016.

36. Jha JC, Gray SP, Barit D, Okabe J, El-Osta A, Namikoshi T, Thallas-Bonke V, Wingler K, Szyndralewiez C, Heitz F, et al: Genetic targeting or pharmacologic inhibition of NADPH oxidase nox 4 provides renoprotection in long-term diabetic nephropathy. J Am Soc Nephrol 25: 1237-1254, 2014.
37. Sun YM, Su Y, Li J and Wang LF: Recent advances in understanding the biochemical and molecular mechanism of diabetic nephropathy. Biochem Biophys Res Commun 433: 359-361, 2013.

38. Pichaiwong W, Hudkins KL, Wietecha T, Nguyen TQ, Tachaudomdach C, Li W, Askari B, Kobayashi T, O'Brien KD, Pippin JW, et al: Reversibility of structural and functional damage in a model of advanced diabetic nephropathy. J Am Soc Nephrol 24: 1088-1102, 2013.

39. Kolset SO, Reinholt FP and Jenssen T: Diabetic nephropathy and extracellular matrix. J Histochem Cytochem 60: 976-986, 2012.

40. Lenihan CR, Busque S, Derby G, Blouch K, Myers BD and Tan JC: Longitudinal study of living kidney donor glomerular dynamics after nephrectomy. J Clin Invest 125: 1311-1318, 2015.

41. Song KH, Park J, Park JH, Natarajan R and Ha H: Fractalkine and its receptor mediate extracellular matrix accumulation in diabetic nephropathy in mice. Diabetologia 56: 1661-1669, 2013.

42. Pieri M, Stefanou C, Zaravinos A, Erguler K, Stylianou K, Lapathitis G, Karaiskos C, Savva I, Paraskeva R, Dweep H, et al: Evidence for activation of the unfolded protein response in collagen IV nephropathies. J Am Soc Nephrol 25: 260-275, 2014.

43. Yap WT, Salvay DM, Silliman MA, Zhang X, Bannon ZG, Kaufman DB, Lowe WL Jr and Shea LD: Collagen IV-modified scaffolds improve islet survival and function and reduce time to euglycemia. Tissue Eng Part A 19: 2361-2372, 2013.

44. Yung S, Ng CY, Ho SK, Cheung KF, Chan KW, Zhang Q, Chau MK and Chan TM: Anti-dsDNA antibody induces soluble fibronectin secretion by proximal renal tubular epithelial cells and downstream increase of TGF- $\beta 1$ and collagen synthesis. J Autoimmun 58: 111-122, 2015

45. Tang O, Chen XM, Shen S, Hahn M and Pollock CA: miRNA-200b represses transforming growth factor- $\beta 1$-induced EMT and fibronectin expression in kidney proximal tubular cells. Am J Physiol Renal Physiol 304: F1266-F1273, 2013.

46. Knowles LM, Gurski LA, Maranchie JK and Pilch J: Fibronectin matrix formation is a prerequisite for colonization of kidney tumor cells in fibrin. J Cancer 6: 98-104, 2015.

47. Liu JQ, Lee TF, Miedzyblocki M, Chan GC, Bigam DL and Cheung PY: Effects of tanshinone IIA, a major component of Salvia miltiorrhiza, on platelet aggregation in healthy newborn piglets. J Ethnopharmacol 137: 44-49, 2011.

48. Ahn YM, Kim SK, Lee SH, Ahn SY, Kang SW, Chung JH, Kim SD and Lee BC: Renoprotective effect of Tanshinone IIA, an active component of Salvia miltiorrhiza, on rats with chronic kidney disease. Phytother Res 24: 1886-1892, 2010.

49. Wang JG, Pimenta E and Chwallek F: Comparative review of the blood pressure-lowering and cardiovascular benefits of telmisartan and perindopril. Vasc Health Risk Manag 10: 189-200, 2014.

This work is licensed under a Creative Commons Attribution-NonCommercial-NoDerivatives 4.0 International (CC BY-NC-ND 4.0) License. 